\title{
A Review of Impact of COVID-19 Pandemic on Medical and Healthcare Fraternity
}

\author{
Aishwarya Uday Beedkar \\ Medical Intern, Department of Community Medicine, Jawaharlal Nehru Medical College, \\ Datta Meghe Institute of Medical Sciences, Sawangi (Meghe), Wardha (442001). \\ Corresponding author email: ashbeedkar@gmail.com
}

\section{ABSTRACT}

Covid-19 caused by the SARS-COV-2 virus (severe acute respiratory syndrome Coronavirus 2), is a severe disease which we became cognizant of only six months ago. Six months, which resulted in profound changes in business, education, transportation, and almost every aspect of daily life. Millions have been affected and thousands have lost their lives. It would not be a stretch to call this a war. And in the vanguard of this war is the Medical fraternity. As such, the impact of COVID-19 on all components of Health-care is undeniable. From medical students to consultant specialists, from government healthcare workers to private practitioners, every echelon of the medical world has been affected. This has been a challenge of unprecedented proportions, especially for the Indian health-care system. Covid-19 has created a situation of fear and panic in the society. Medical professionals are at the forefront of fighting this disease and naturally come in contact with the patients. Due to this, there have been many cases of discrimination against the individuals. Reports of people asking post graduate students to evacuate their houses with no prior warning were prevalent in the news. Such students were left abandoned only for doing their jobs. Ostracizing of medical professionals by society in general while they battle the deadly disease is extremely disheartening. Covid-19 has irreversibly affected the Medical fraternity. This article attempts to compile the impact of Covid-19 pandemic on medical fraternity and healthcare system.

KEY WORDS: MEDICAL FRATERNITY, MEDICAL EDUCATION, COVID-19, IMPACT, STUDENTS, SUFFERINGS, DISCRIMINATION.

\section{INTRODUCTION}

Covid-19 caused by the SARS-COV-2 virus (severe acute respiratory syndrome Coronavirus 2), is a severe disease which we became cognizant of only six months ago. Six months, which resulted in profound changes in business, education, transportation, and almost every aspect of daily life. Millions have been affected and thousands have lost their lives. It would not be a stretch to call this a war. And in the vanguard of this war is the Medical fraternity. As such, the impact of COVID-19 on all

Biosc Biotech Res Comm P-ISSN: 0974-6455 E-ISSN: 2321-4007

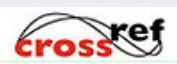

Identifiers and Pagination

Year: 2021 Vol: 14 No (6) Special Issue

Pages: $247-252$

This is an open access article under Creative

Commons License Attribn 4.0 Intl (CC-BY).

DOI: http://dx.doi.org/10.21786/bbrc/14.6.51 components of Health-care is undeniable. From medical students to consultant specialists, from government healthcare workers to private practitioners, everyechelon of the medical world has been affected. This has been a challenge of unprecedented proportions, especially for the Indian health-care system.

On 12th of January 2020, the World Health Organization (WHO), confirmed that a novel Coronavirus was responsible for a type of respiratory disease in a group of people in the Wuhan province of China. On 30 January 2020 India reported its first case of COVID-19 in Kerala, which increased to three cases by February. All cases were reported to be students returning from Wuhan. First confirmed death due to Coronavirus in India was reported on 12th March 2020. On 15th March India had 100 confirmed cases. In response to this the Prime Minister of India announced a voluntary Janta Curfew to be observed on 22nd March. It is to be noted that on this day, at $5 \mathrm{pm}$, across the nation, people showed support

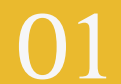


and appreciation for Healthcare workers, Police, and all the other providers of essential services by clapping, banging utensils etc. This became a topic of much controversy. Finally, on 25th March 2020, a nationwide lockdown was imposed.

\section{Figure 1}

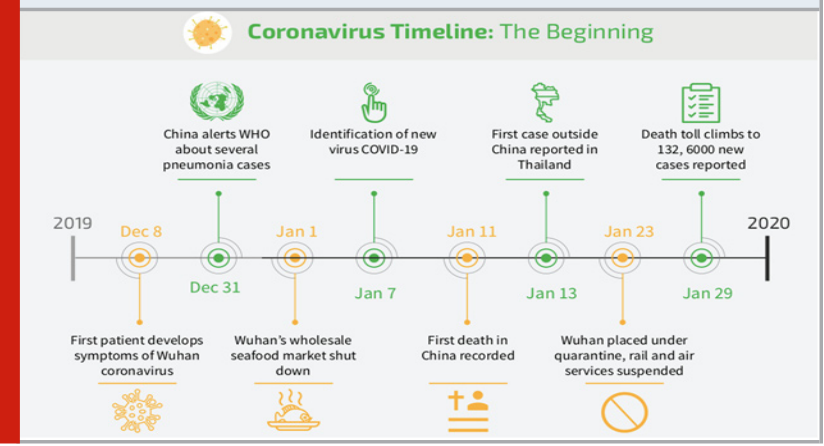

Impact of Covid-19 on medical Education: Medical colleges across the nation had to suspend classes and students were advised to return to their homes. In a never seen before scenario, medical education was moved to the online platform with classes taken through video conferencing. The practical aspect of medical education certainly suffered due to this, as it was virtually impossible for students to come in contact with patients. Compensating for this deficiency in practical hands on education is going to be one of the most important challenges of moving forward for medical students. Recently due to the rising cases of violence against doctors, the importance of communication and empathy in medical education has been emphasized.

\section{Figure 2}

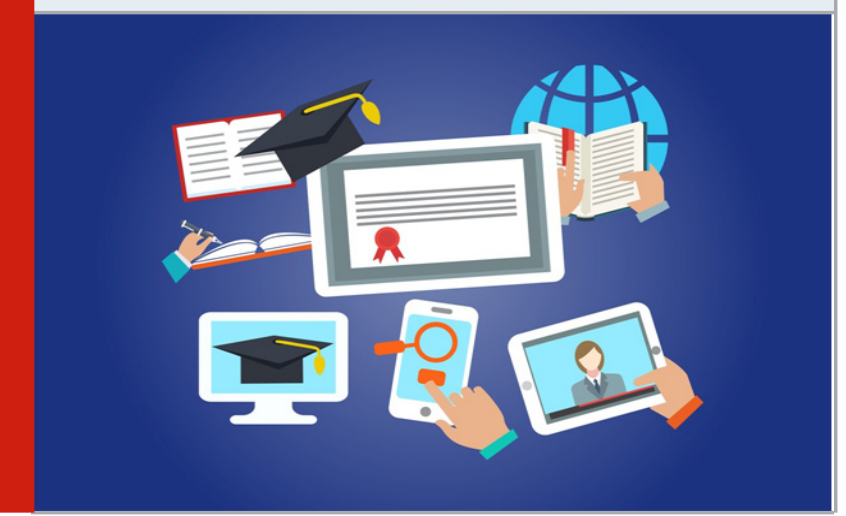

Special lectures to teach behavior, empathy, communication skills have been included in the curriculum. One of the most important part of this is facial expressions. But since the advent of Covid-19 masks have become essential, and hence it is difficult to gauge the expressions of a person. This might result in a communication gap, and the responsibility of working around this falls to the doctor. As a medical student one is also taught the importance of odor, especially in a person's breath to make a diagnosis. Alcoholic breath, fetor hepaticus, halitosis and so on have been important diagnostic tools, but this will also have to be re-evaluated. The manner of evaluating patients of pyrexia of unknown origin will also be drastically changed as each case might be considered to be a potential Covid-19 case. These and many other issues shall certainly change the manner of medical education not just in India but throughout the world.

Impact at intern and post graduate level: Interns and post graduate students are an important part of the work force fighting the disease. They form the front-line of professionals dealing with patient care. They are among the ones with highest risk of being infected. Delaying of post graduate examinations resulted in difficulties. Admissions could not take place as scheduled which resulted in short staffing, especially in areas which faced a high burden of cases. Unavailability of personal protective equipment, shortage of masks, sanitizers et all was also a challenge that impacted the interns andpost graduate students actively fighting the disease. Incentives which included hikes in stipends were released. Risk of procuring infection still remains a deterrent for voluntary work, despite the incentives. Longer work hours, physical as well as psychological stress and fatigue are additional hazards that have to be faced. Another important challenge is educating the students while they work to tackle the crisis.

Post graduates and interns need to be aware of the presentation of the disease, it's progression as well as any new advancements in the understanding. It is important to remain constantly updated as new information regarding the virus, its pathophysiology, symptoms, signs as well as treatment is emerging every day. This is the responsibility of not just specialists and physicians but also of students, interns and post graduates. Despite all challenges the students across specialties have risen to do their duty in time of need which is certainly commendable.

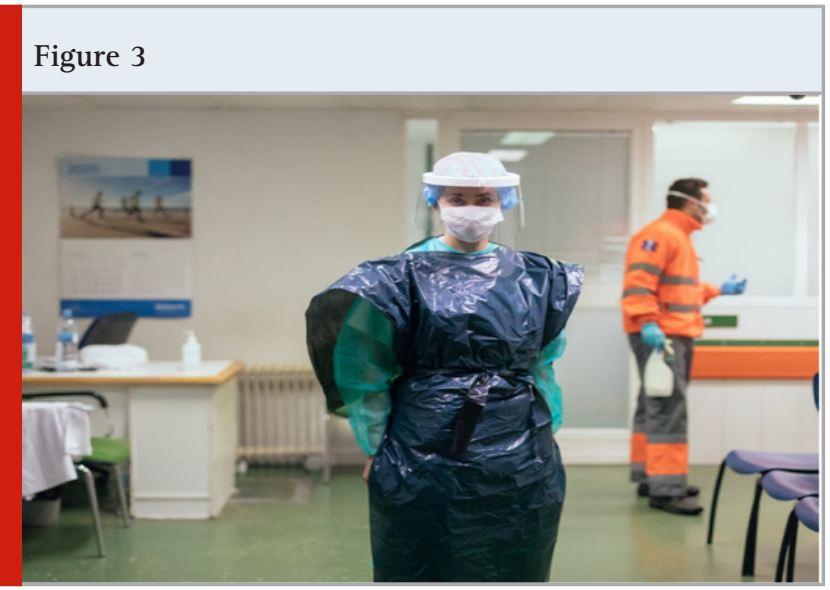

Impact over Practicing Doctors: Covid-19 is the latest threat to global health. The greatest challenge of the disease is its unpredictability. Understanding the disease, the virus that causes it, its presentation, finding a cure as well as researching preventive methods including vaccination is under the purview of the medical 
community. Doctors and researchers from various countries like United States, China, Russia, Italy, and India et.all are working towards these goals. The medical community in India needs to be geared up to face the challenge but it is important to also understand the impact of this challenge on the doctors.

Physicians and respiratory specialists are the most equipped in treatment of the disease as it primarily affects the respiratory system. Intensive care has a very important role and anesthesiologists are also essential in dealing with severe cases. In areas with high number of cases doctors from all branches of medicine have joined in treatment of the disease. Naturally, they are at a very high risk of procuring infection. It has become very important for Heath care workers to protect themselves by following all measures of safety. What makes it even more challenging is the concealment of travel history by patients. In addition to this, due to increased work load in special Corona wards, burn out due to fatigue is a very real possibilities. Those that care for the health of society in these trying times need to take care of their own health too, both physical as well as mental.

Pictures of doctors and nurses improvising with other materials due to the lack of personal protective equipment kits have appeared on the internet (Sophia Ankel 2020). Whereas nurses in the United States have been protesting over the unavailability of PPE (Rhea Mahbubani 2020). Covid-19 has affected all branches of medicine. Especially ones that require regular and close contact with patients like Ophthalmology, Otorhinolaryngology, et all. Elective procedures have also been stopped. Tele medicine has gained increased importance during this time period. The relationship between doctors and patients has also been affected. It can be conclusively said that the pandemic of Covid-19 has made some unalterable changes in the way patients will be diagnosed and treated in the future.

Impact over private practice: Governmental institutions are dealing with the brunt of the disease, yet its impact on private practice has also been noted. Quickly identifying potential cases and diverting them to government hospitals is one of the major challenges faced by private practitioners. Transportation ban, stoppage of elective procedures has also impacted private practice. Economically, private practice has taken a hit due to the pandemic. Major revenue from outpatient departments (OPD) and elective procedures has come to a stop and this has led to financial deterioration with little hope of any subsidization.

In areas with high burden of cases, private hospitals have been notified to arrange for dealing with Covid19 cases. This has a significant impact on the staff as well as doctors who may not have imagined such a situation or might not be equipped to handle these cases (Sumitra Debroy,et al 2020, Indranil Mukherjee 2020, Sanchita Sharma, Annona Dutt 2020 and Ashwini Priolker 2020). Another big risk for private hospitals is the risk of having their entire hospital sealed if any case of COVID-19 is discovered which leads to financial, as well as psychological problems.

One of the major and less talked about part of the disease is the rumor mongering in context of private hospitals. The disease has given rise to a state of palpable fear among society at large. Rumors are the result of this fear. Many times false rumors regarding emergence of cases in hospitals are spread due to which the staff and doctors of the hospital are affected. The patients in the hospital get disturbed. This leads to increased fear and disturbance among doctors, staff and patients. Such rumor mongering needs to be contained since it may lead to a damage that might be irreparable. The psychological impact over doctors has to be taken in consideration. Punitive measures regarding such behavior are absolutely necessary. BMC has directed various private hospitals to start isolation wards, according to an article in Times of India.

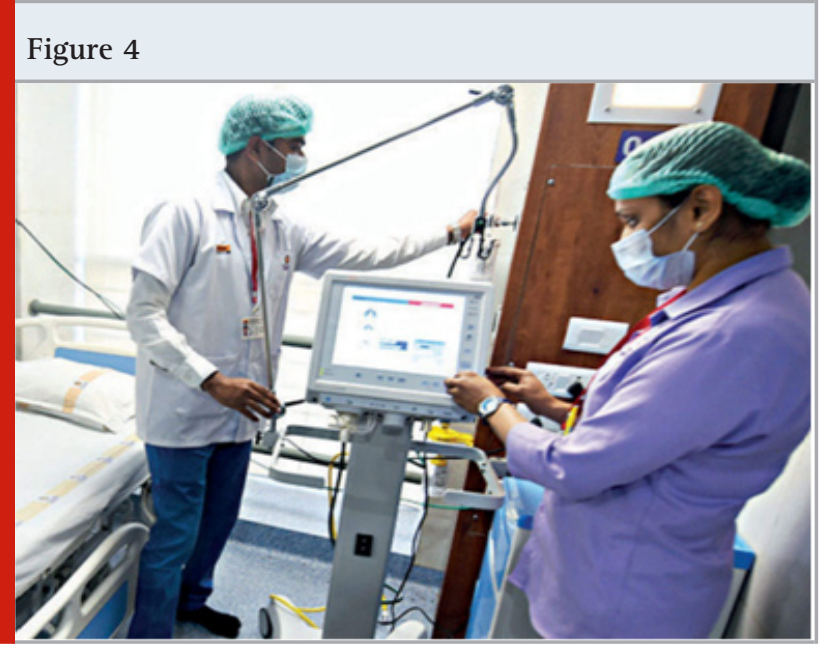

Discrimination faced by Medical Professionals: Covid-19 has created a situation of fear and panic in the society. Medical professionals are at the forefront of fighting this disease and naturally come in contact with the patients. Due to this, there have been many cases of discrimination against the individuals. Reports of people asking post graduate students to evacuate their houses with no prior warning were prevalent in the news. Such students were left abandoned only for doing their jobs. Ostracizing of medical professionals by society in general while they battle the deadly disease is extremely disheartening. Rumors being spread about positive cases in certain hospitals led to boycott of such hospitals. Such cases of negativity among the society towards medical professionals have caused distress and inconvenience (Indulekha Aravind 2020, Jessie Yeung, Swati Gupta 2020, Aditya Kalra, Devjyot Ghoshal 2020 and Neetu Chandra Sharma 2020).

Impact on Mental Health: Medical and paramedical staffcannot hole up in their homes to keep themselves safe from the disease. They must wake up daily and rush to their dutiesdespite being aware that they are vulnerable to risk. For protection of their families they 
are also forced to isolate themselves. Aside from the lack of personal protective equipment, stress of working round the clock, the constant anxiety of being infected has also added to the mental health issues. This is especially true for those frontline healthcare workers that are working in hotspots. Making sure ofthe physical as well as mentalsafety and protection of medical and paramedical frontline workers should be an important part of the public health domainin addressing the pandemic.

However, the correct mental health counseling can help increaseperseverance, providingmedical fraternity the confidence to manage stress in the future times. It is important to understand that improving mental healthcarefacilities is an ever going process. We need to think about many factors, such as the countrywide shortage of psychiatrists and the obstacles in the path ofproviding tele medical services. Tele therapy, virtual mental health services, and meditation apps have started emerging after the nation's government announced the countrywide lockdown, and they should be promoted and made available to healthcare workers too.

In all countries of theworld, people under lockdown gathered in their balconies to give appreciation and show gratefulness for healthcare workers who are risking their own lives and that of their families to save others. Social media posts are full of people givinggrateful messages to healthcare workers. While these gestures can increase the morale and motivate toan extent, it is important to understand that hero-worship in isolation is not going to protect them from the mental anguish they face daily. Like heroescoming back from war, it is going to take time for them to process everything they are going through and heal. They will certainly face a fork of post traumatic stress disorder just like soldiers do. Once the physical health crisis ends, we need to enforce and prepare ourselves for a mental health crisis. Meditation, mindfulness practices, counselling and support can play a significant part in bringing the inner peace and restoring the 'restfulness' amidst this chaos (Dr. Pankaj Gupta, 2020).

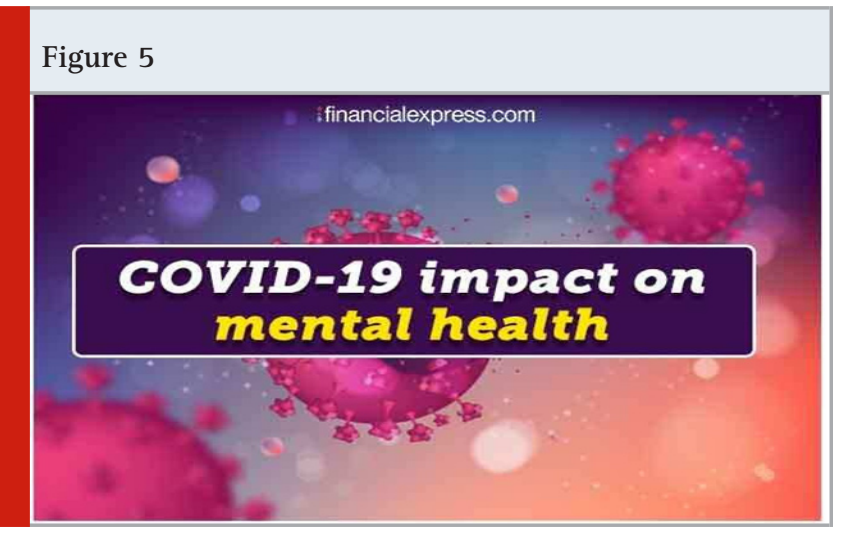

DISCUSSION AND CONCLUSION

Covid-19 has affected all parts of society, and the medical fraternity is one of the most affected. (Somashekahar et $\mathrm{al}, 2020)$ reviewed the ASI's Consensus Guidelines to be followed in Covid 19. (Spoorty et al, 2020) have reviewed about mental health problems faced by healthcare workers due to the Covid-19 pandemic. Risk factors of respiratory health issues in this region are evident from the previous studies (Taksande, et al 2016, Dhar,et al 2019, Salampuria, et al 2019 and Dhar, R., et al 2017). Reviews on effects of Covid on healthcare industry were reported (Prasad, N., et al 2020, Sharma, D. 2020, Sheikh, M.K., et al 2020, Sheikh, M.K., et al 2020 and Anjankar, V.P., et al 2020). (Bawiskar et.al 2020) reported about haematological Manifestations of Covid19. (Godhiwala et.al. 2021) reported about leukemoid reaction in a COVID-19. (Gupta et.al. 2020) discussed on use of nitrous oxide-oxygen inhalation sedation in the COVID-19 Era. (Hande et.al. 2021) suggested modalities to restrain the progression of oral potentially malignant diseases patients in Covid-19. Studies by (Bidkar et.al. 2021 and Dasari et.al. 2020) were reviewed.Now the doctors have become soldiers. All parts of the medical community from education to professional practice have been irreversibly affected. To take this forward and rebuild from this experience is bound to be an uphill task. But the medical fraternity shall undeniably rise to the challenge and emerge stronger as well as wiser.

\section{Conflict of Interest: None.}

\section{Funding: DMIMS, Wardha}

\section{REFERENCES}

Aditya Kalra, Devjyot Ghoshal, 2020. Indian Doctors Evicted Over Coronavirus Transmission Fears, Says Medical Body-- https://science.thewire.in/health/ indian-doctors-evicted-over-coronavirus-transmissionfears-says-medical-body

Anjankar, V.P., Anjankar, A.P. and Anjankar, A.J., 2020. Review of the Impact of COVID-19 on Medical Education System. Int J Cur Res Rev| Vol, 12(20), p.183.

Ashwini Priolker, 2020. Coronavirus Outbreak: Private Hospitals, Labs in Mumbai to conduct Covid-19 Tests19 March 2020-https://www.bloombergquint.com/ coronavirus-outbreak/coronavirus-outbreak-privatehospitals-labs-in-mumbai-to-conduct-covid-19-tests Bawiskar, N., Andhale, A., Hulkoti, V., Acharya, S. and Shukla, S., 2020. Haematological Manifestations of Covid-19 and Emerging Immunohaematological Therapeutic Strategies. Journal of Evolution of Medical and Dental Sciences, 9(46), pp.3489-3495.

Beedkar, A.U. and Funding-DMIMS, W., 2020. Covid-19 and its impact on medical fraternity. European Journal of Molecular \&t Clinical Medicine, 7(11), pp.31663174.

Bidkar, V., Selvaraj, K., Mishra, M., Shete, V. and Sajjanar, A., 2021. A comparison of swab types on sample adequacy, suspects comfort and provider preference in COVID-19. American Journal of Otolaryngology, 42(2), 
p.102872.

DASARI, V. and DASARI, K., 2020. Nutraceuticals to Support Immunity: COVID-19 Pandemic-A Wake-up Call. Journal of Clinical \&t Diagnostic Research, 14(7). Dhar, R., Mohan, M., D’souza, G., Rajagopalan, S., Singh, V., Jindal, A., Ghewade, B., Joshi, G., Sahasrabuddhe, T., Gami, S. and Nair, G., 2017. Phenotype characterization of non cystic fibrosis bronchiectasis in India: baseline data from an Indian bronchiectasis registry. In B103. CLINICAL STUDIES IN BRONCHIECTASIS, IMMUNODEFICIENCY, AND DRUG INDUCED LUNG DISEASE (pp. A4726-A4726). American Thoracic Society.

Dhar, R., Singh, S., Talwar, D., Mohan, M., Tripathi, S.K., Swarnakar, R., Trivedi, S., Rajagopala, S., D’Souza, G., Padmanabhan, A. and Baburao, A., 2019. Bronchiectasis in India: results from the European multicentre bronchiectasis audit and research collaboration (EMBARC) and respiratory research network of India registry. The Lancet Global Health, 7(9), pp.e1269e1279.

Dr. Pankaj Gupta, 2020. How COVID-19 is affecting the mental health of doctors and nurses?- https:// www.financialexpress.com/lifestyle/health/how-covid19-is-affecting-the-mental-health-of-doctors-andnurses/1973490.

Gupta, K., Emmanouil, D. and Sethi, A., 2021. Use of nitrous oxide-oxygen inhalation sedation in the COVID-19 era. International Journal of Paediatric Dentistry, 31(3), pp.433-435.

Hande, A., Sonone, A., Gadbail, A., Gawande, M., Patil, S. and Sharma, P., 2020. Modalities to restrain the progression of oral potentially malignant diseases and oral squamous cell carcinoma in COVID-19 pandemic. Oral Oncology.

Indranil Mukherjee 2020. Covid-19: BMC to take over one private hospital in every ward to provide for 2,400 additional beds- https://scroll.in/latest/962548/covid19-bmc-to-take-over-one-private-hospital-in-everyward-to-provide-for-2400-additional-beds

Indulekha Aravind, 2020. Coronavirus Pandemic: Healthcare professionals take to social media to express their despair- https://economictimes. indiatimes.com/industry/healthcare/biotech/healthcare/ healthcare-pros-take-to-social-media-to-expresstheir-espair/articleshow/74818703. cms?utm_ source $=$ contentofinterestCtutm_medium =textCtutm campaign $=$ cppst

Jessie Yeung, Swati Gupta, 2020. Doctors evicted from their homes in India as fear spreads amid coronavirus lockdown- https://edition.cnn.com/2020/03/25/asia/ india-coronavirus-doctors-discrimination-intl-hnk/ index.html
Latchoumi, T.P., Ezhilarasi, T.P. and Balamurugan, K., 2019. Bio-inspired weighed quantum particle swarm optimization and smooth support vector machine ensembles for identification of abnormalities in medical data. SN Applied Sciences, 1(10), pp.1-10.

Ministry of Health and family welfare- Update on COVID-19: two more positive cases reported- 02 March 2020 - https://pib.gov.in/PressReleseDetail. aspx?PRID=1604813

Neetu Chandra Sharma, 2020- Doctors, nurses face stigma over coronavirus, asked to vacate rented homeshttps://www.livemint.com/news/india/doctors-nursesface-stigma-over-coronavirus-asked-to-vacate-rentedhomes-11585074366997.html

Prasad, N., Bhatt, M., Agarwal, S.K., Kohli, H.S., Gopalakrishnan, N., Fernando, E., Sahay, M., Rajapurkar, M., Chowdhary, A.R., Rathi, M. and Jeloka, T., 2020. The adverse effect of COVID pandemic on the care of patients with kidney diseases in India. Kidney international reports, 5(9), pp.1545-1550.

Salampuria, S., Jajoo, S. and Acharya, S., 2019. Acute respiratory distress syndrome during pregnancy and post-partum-a case series with spectrum of near miss to mortality. Journal of Evolution of Medical and Dental Sciences-JEMDS, 8, pp.3724-26.

Sanchita Sharma, Annona Dutt 2020. Covid-19 pandemic forces hospitals to scale up-- https:// www.hindustantimes.com/india-news/covid-19pandemic-forces-hospitals-to-scale-up/story7iRDBFUC4V5Xk9SgNA6fxM.html

Sharma, D., Preventive Measures for COVID-19 Health Care Professionals. International Journal of Research in Pharmaceutical Sciences, 11, pp.1307-12.

Sheikh, M.K., Chaudahry, N. and Ghogare, A., 2020. Depression in Teachers Due to Cyberbullying Who are Working in COVID-19 Pandemic: A Cross-Sectional Study. International Journal of Current Research and Review, pp.98-102.

Sheikh, M.K., Malavde, R. and Daigavane, S., 2020. Yogic Eye Exercises Followed by the Ergonomic Advice on Eye Fatigue in Children Attending Online Classes in COVID-19. International Journal of Current Research and Review, 12, pp.132-36.

Somashekhar, S.P., Shivaram, H.V., Abhaham, S.J., Dalvi, A., Kumar, A., Gode, D., Misra, S., Jain, S.K., Prasad, C.R.K. and Pillarisetti, R.R., 2020. ASI's consensus guidelines: $\mathrm{ABCs}$ of what to do and what not during the COVID-19 pandemic.

Spoorthy, M.S., Pratapa, S.K. and Mahant, S., 2020. Mental health problems faced by healthcare workers due to the COVID-19 pandemic-A review. Asian journal of psychiatry, 51, p.102119

Sumitra Debroy, Vijay V singh 2020. Covid-19 scare: BMC 
directs nine private hospitals to start isolation wardshttps://timesofindia.indiatimes.com/city/mumbai/ covid-19-scare-bmc-directs-nine-private-hospitals-tostart-isolation-wards/articleshow/74701868.cms Taksande, A.M. and Yeole, M., 2016. Risk factors of Acute Respiratory Infection (ARI) in under-fives in a rural hospital of Central India. Journal of Pediatric and Neonatal Individualized Medicine (JPNIM), 5(1), pp.e050105-e050105.

Tanita, L., 2020. The COVID-19 Safety and Health Accreditation Program: How Food Safety Inspectors and Building Inspectors Can Incentivize OSHA Compliance to Protect Workers During the Coronavirus Pandemic. Tarekegn, K., Ramos, A.C., Gross, H.G.S., Yu, M. and Fulger, I., 2021. Leukemoid Reaction in a Patient With
Severe COVID-19 Infection. Cureus, 13(2).

TWC India Edit Team- Kerala Defeats Coronavirus; India's Three COVID-19 Patients Successfully Recover14 February 2020- https://weather.com/en-IN/india/ news/news/2020-02-14-kerala-defeats-coronavirusindias-three-covid-19-patients-successfully

Vijay V Singh, Malathilyer, 2020. 80 per cent of private hospital beds to be reserved for Covid-19 emergency patients:BMC- - http://timesofindia. indiatimes.com/articleshow/75819729.cms?utm source=contentofinterest\&utm_medium=text\&utm_ campaign=cppst

Wikipedia.in- Timeline of covid-19 pandemic in Indiahttps://en.wikipedia.org/wiki/Timeline_of_the_COVID19_pandemic_in_India 